\title{
Análise da correlação entre os níveis séricos da vitamina $D$ e os níveis de OPG/RANKL intraósseo
}

\author{
Analysis of the correlation between serum vitamin D and intraosseous OPG/RANKL levels \\ Análisis de la correlación entre los niveles séricos de vitamina D y los niveles intraóseos \\ de OPG/RANKL
}

Thalita Alves Barreto Santos ${ }^{1}$, Ricardo Villas-Boas ${ }^{1}$, Carlos Henrique Ramirez Nunes ${ }^{1}$, Marina Prado Fernandes Pinheiro ${ }^{1}$, Patricia Cataldo de Felipe Cordeiro ${ }^{1}$, Mariana Campello Nunes ${ }^{1}$, Leticia Ladeira Bonato ${ }^{1}$, Jose de Albuquerque Calasans-Maia ${ }^{1}$, Priscila Ladeira Casado ${ }^{1}$ Valquiria Quinelato ${ }^{1 *}$.

\section{RESUMO}

Objetivo: Avaliar se os níveis de vitamina $\mathrm{D}$ séricos tem correlação com os níveis intraósseos de $O P G$ (Osteoprotegerina) / RANKL (ligante do receptor ativador do fator nuclear kappa Beta (NF-kB)). Métodos: Oito participantes de pesquisa selecionados no curso de especialização em Implantodontia da Universidade Federal Fluminense foram incluídos neste estudo piloto e divididos em 2 grupos: 1) grupo controle (nível sérico adequado de vitamina $D ; n=5$ ) e 2) grupo teste (insuficiência de vitamina $D$ sérica; $n=3$ ). Amostras de sangue intraósseo foram coletadas no alvéolo cirúrgico, no momento da instalação do implante, e submetidas ao isolamento de RNA total usando o reagente Trizol $\Theta$. A reação de transcriptase reversa foi realizada para síntese do $D N A$ complementar $(c D N A)$ usando $300 \mathrm{ng}$ de RNA. A expressão dos genes OPG e RANKL foi avaliada pela reação em cadeia da polimerase quantitativa (RT-PCR), utilizando o sistema de detecção SYBR Green Master Mix. Resultados: Não foram observadas diferenças estatísticas entre os grupos, em relação à análise de expressão gênica de OPG/RANKL $(\mathrm{p}=0.78), O P G(\mathrm{p}=0.5)$ e RANKL $(\mathrm{p}=0.5)$. Conclusão: Os resultados deste estudo piloto não evidenciaram correlação entre alterações nos níveis séricos de vitamina $\mathrm{D}$ e marcadores da remodelação óssea.

Palavras-chave: Expressão gênica, Osteoprotegerina, Remodelação óssea, RANKL, Vitamina D 3.

\begin{abstract}
Objective: To evaluate the correlation between serum vitamin $\mathrm{D}$ levels and intraosseous levels of $O P G$ (Osteoprotegerin) / RANKL (kappa nuclear factor activator receptor (NF-kB) ligand). Methods: Eight research participants selected at the Post-graduation in Implant Dentistry at Universidade Federal Fluminense were included in this pilot study, and divided into 2 groups: 1) control group (adequate serum vitamin $D$ level; $n=5$ ) and 2) test group (insufficient serum vitamin $D ; n=3$ ). Intraosseous blood samples were collected in the surgical socket at the time of implant placement, and processed to total RNA isolation by using the Trizol $\AA$ reagent. A reverse transcriptase reaction was performed to synthesize complementary DNA (cDNA) using $300 \mathrm{ng}$ of RNA. The expression of the OPG and RANKL genes was evaluated by the quantitative polymerase chain reaction (RT-PCR), using the SYBR Green Master Mix detection system. Results: There were no statistical differences between groups in relation to the analysis of gene expression of OPG / RANKL ( $\mathrm{p}=0.78), O P G(\mathrm{p}=0.5)$ and RANKL $(\mathrm{p}=0.5)$. Conclusion: The results of this study did not show changes between serum vitamin $D$ levels and bone remodeling biomarkers.
\end{abstract}

Keywords: Gene expression, Osteoprotegerin, Bone remodeling, RANKL, Vitamin D 3.

\section{RESUMEN}

Objetivo: Evaluar si los niveles séricos de vitamina $D$ se correlacionan con los niveles intraóseos de $O P G$ (osteoprotegerina) / RANKL (ligando del receptor del activador del factor nuclear kappa (NF-kB)). Métodos: En este estudio piloto se incluyeron ocho participantes de investigación seleccionados en el curso de especialización en Implantología de la Universidade Federal Fluminense y se dividieron en 2 grupos: 1) grupo control (nivel adecuado de vitamina $D$ en suero; $n=5$ ) y 2) grupo de prueba (suero insuficiencia de vitamina $D ; n=3$ ). Se recogieron muestras de sangre intraósea en el alveolo quirúrgico en el momento de la instalación del implante y se sometieron a aislamiento total de ARN utilizando el reactivo Trizol®. Se realizó una reacción de transcriptasa inversa para sintetizar ADN complementario (ADNc) utilizando $300 \mathrm{ng}$ de ARN. La expresión de los genes OPG y RANKL se evaluó mediante la reacción cuantitativa en cadena de la polimerasa (RT-PCR), utilizando el sistema de detección SYBR Green Master Mix. Resultados: No hubo diferencias estadísticas entre grupos en relación al análisis de expresión génica de OPG / RANKL $(\mathrm{p}=0,78), O P G(\mathrm{p}=0,5)$ y RANKL $(\mathrm{p}=0,5)$. Conclusión: Los resultados de este estudio no mostraron cambios entre los niveles séricos de vitamina $\mathrm{D}$ y los marcadores de remodelación ósea.

Palabras clave: Expresión génica, Osteoprotegerina, Remodelación ósea, RANKL, Vitamina D 3.

${ }^{1}$ Universidade Federal Fluminense (UFF), Niterói - RJ. *E-mail: valquiriaquinelato@yahoo.com.br 


\section{INTRODUÇÃO}

A prática odontológica engloba uma série de procedimentos, cirúrgicos e conservadores, dependentes da adequada regeneração do tecido ósseo para suportar a reabilitação clínica do paciente (BOONSIRISETH K, et al., 2014).

O processo de regeneração é comum à todas as feridas, independentemente do agente que a causou, sendo sistêmico e dinâmico, e está diretamente relacionado às condições gerais do organismo (BROUGHTON G, et al., 2006). A regeneração de feridas consiste em perfeita e coordenada sequência de eventos moleculares, celulares e bioquímicos que interagem para que ocorra a recomposição tecidual. Carrel A (1910) descreveu os mecanismos da regeneração numa sequência ordenada de eventos, divididos, posteriormente, em cinco elementos principais: inflamação, proliferação celular, formação do tecido de granulação, contração e remodelamento da ferida (CARREL A, 1910; ORGILL D, DEMLING RH, 1988). Clark DA (2005), reclassificou esse processo em três fases: inflamatória, proliferativa e remodelação.

A fase inflamatória inicia-se após a ocorrência da lesão tecidual e se divide em duas partes: formação de coágulos sanguíneos e migração de células da inflamação (ARAÚJO MG, et al., 2015). Na fase proliferativa ocorre a proliferação dos fibroblastos, dando origem à um processo chamado fibroplasia, onde os fibroblastos sintetizam os componentes da matriz extracelular. Concomitantemente, ocorre a proliferação de células endoteliais, neoangiogênese, e infiltração densa de macrófagos, formando o tecido de granulação (TAZIMA MFGS, et al., 2008).

No momento do procedimento cirúrgico ósseo, há formação do coágulo, e reabsorção de resíduos celulares e matriz óssea, dando início à proliferação de tecido conjuntivo, a partir de células do periósteo e do endósteo, que resulta na formação de tecido ósseo imaturo, que sofrera posterior remodelação, estabelecendo um tecido ósseo maduro (LIMA RSR e SEABRA FRG, 2010).

Dentro desse conceito, a vitamina $D$ atua no processo de remodelação óssea, o qual requer a aposição óssea por osteoblastos e a reabsorção por osteoclastos. A deficiência de vitamina $D$ resulta em anormalidades no metabolismo de cálcio e de fósforo. A principal função da vitamina $D$ é manter as concentrações séricas de cálcio dentro de um intervalo aceitável, fisiologicamente. Esta função é exercida através do aumento da absorção intestinal do cálcio. No estado de deficiência de vitamina $D$, o intestino absorve em torno de $10-15 \%$ de cálcio na dieta. No estado de suficiência de vitamina D, normalmente $30 \%$ é absorvida a partir da dieta, 60-80\% pode ser absorvido durante o crescimento, gravidez ou lactação, conforme o aumento da demanda por cálcio (HOLICK MF, 1994; HOLICK MF, 2004).

Vitamina $D$ é um termo que engloba um conjunto de moléculas secosteroides originárias do 7deidrocolesterol (7-DHC). Essas moléculas são conectadas entre si por meio de reações fotolíticas e enzimáticas que ocorrem em diferentes células de diversos tecidos. Essa denominação abrange tanto o metabólito ativo desta vitamina (1 $\alpha, 25$-diidroxi-vitamina $D$ ou calcitriol) assim como seus precursores (sendo eles a vitamina D3 ou colecalciferol, vitamina D2 ou ergosterol e a 25 -hidroxivitamina D ou calcidiol). Seus produtos de degradação que mantêm alguma atividade metabólica também são incluídos neste grupo (BOUILLON R, et al., 1995; NORMAN AW, 2008).

A forma ativa da vitamina $D$, a 1a,25-diidroxi-vitamina $D(1,25(\mathrm{OH}) 2 \mathrm{D})$, na realidade, é um hormônio esteroide componente do eixo metabólico do sistema endocrinológico vitamina D. A formação desse sistema compreende várias moléculas que compõem o grupo vitamina $D$, assim como sua proteína carreadora (DBP, vitamin D binding protein), seu receptor (VDR, vitamin $D$ receptor) e, ainda, por outras enzimas (BOUILLON R, et al., 1995; NORMAN AW, 2008).

A atuação da vitamina $D$ em processos metabólicos é pesquisada desde o século XVII e foi objeto do Prêmio Nobel em 1938. Atualmente, são conhecidos aproximadamente 41 metabólitos da vitamina $D$ e um hormônio principal, a 1,25(OH)2D (BOUILLON R, et al., 1995), regulando a transcrição gênica e a função celular em diversos tecidos (BOUILLON R, et al., 2008), principalmente no tecido ósseo, sendo que na osteoclastogênese e na remodelação óssea evidencia-se a interação de três membros da superfamília do 
fator de necrose tumoral (TNF): o ligante do receptor ativador do fator nuclear kappa Beta (NF-kB)-RANKL, o receptor ativador do NF-kB (RANK) e a osteoprotegerina (OPG) (BAUD'HUIN M, et al., 2007; MINE Y, et al., 2010).

A deficiência prolongada de vitamina $D$ provoca a desorganização desse processo e consequentemente leva a patologias como o raquitismo e a osteomalácia. Em adultos, quando associada à osteoporose, leva a um risco aumentado de fraturas (RUIZ-IRASTORZA G, et al., 2008). Quando existe insuficiência de cálcio na dieta, a vitamina $D$ interage com o seu receptor em osteoblastos e induz a expressão do receptor ativador do fator nuclear $\mathrm{kB}$ ligante $(R A N K L)$, que interage com o seu receptor em pré-osteoclastos, induzindo-os a tornarem-se osteoclastos maduros (HOLICK MF, 2003 (a); HOLICK MF, 2003 (b)).

RANKL, também conhecido como TNFSF11, é o décimo primeiro membro da família do ligante OPG, expresso por osteoblastos, células estromais, fibroblastos, células $B$ e células $T$ quando estimuladas por citocinas e lipopolissacarídeos bacterianos (DUTZAN N, et al., 2009; COSTA LC, et al., 2018). Sua ação é conduzida conectando-se ao RANK na superfície das células pré-osteoclastos / osteoblastos, resultando no aumento da atividade dos osteoclastos (COSTA LC, et al., 2018; COCHRAN DL, 2008).

Por outro lado, a OPG, também conhecida como fator inibitório de osteoclastogênese ou TNFRSF11B, é um receptor chamariz circulante solúvel de RANKL que antagoniza a interação RANK-RANKL e, portanto, promove a formação óssea pela inibição da osteoclastogênese (BARTOLD PM, et al., 2010).

Os papéis de RANKL, RANK e OPG, na regulação da osteoclastogênese, têm sido extensivamente estudados desde sua descoberta na década de 1990. Desde então, foram evidenciadas suas importantes implicações na regulação de vários tecidos: remodelação óssea, formação de linfonodos, desenvolvimento de glândulas mamárias e controle da febre. Desordens no sistema RANKL/RANK/OPG estão associadas a certas doenças humanas, inclusive osteoporose pós-menopausa, artrite reumatoide, tumores ósseos e certos tumores metastáticos (THEILL LE, et al., 2002; LUI W, et al., 2014; BALOUL SS, 2016).

Considerando que há poucos relatos na literatura relacionando o papel de OPG/RANKL na cicatrização óssea em Odontologia e o possível potencial de alterações nos níveis séricos de Vitamina D na reabsorção óssea, esse trabalho, tem como objetivo verificar se os níveis de vitamina $D$ tem correlação com os níveis intraósseos de OPG/RANKL.

\section{MÉTODOS}

Este é um estudo piloto, duplo-cego, considerando que os operadores responsáveis pela avaliação da osteointegração e pela análise molecular de OPG/RANKL desconheciam os níveis da vitamina $D$ dos participantes de pesquisa. O estudo foi aprovado pelo Comitê de Ética em Pesquisa da Faculdade de Medicina da Universidade Federal Fluminense sob o parecer número 1.786.797, em 20 de outubro de 2016.

\section{Participantes da Pesquisa}

Oito participantes de pesquisa foram selecionados no curso de especialização em Implantodontia da Faculdade de Odontologia da Universidade Federal Fluminense, a partir de maio de 2017.

Os participantes da pesquisa foram submetidos ao planejamento clínico e tomográfico para a realização dos implantes dentários, de acordo com o protocolo do Curso de Especialização em Implantodontia da UFF.

Todos os participantes da pesquisa receberam a instalação de implante endósseo pela técnica de dois estágios cirúrgicos, de acordo com o protocolo preconizado por (ADELL R, et al., 1981).

\section{Critérios de inclusão/exclusão}

Os participantes da pesquisa tiveram como critérios de inclusão: ter indicação para instalação de, pelo menos, um implante endósseo em região edêntula posterior de mandíbula, sem a colocação de biomateriais; apresentar boa saúde geral; concordar em assinar o Termo de Consentimento Livre e Esclarecido; enquadrar-se na faixa etária entre 18 a 60 anos, concordância em realizar os exames sanguíneos pré-operatórios; não tabagistas. 
Os critérios de exclusão foram: participantes portadores de diabetes mellitus, doença hepática e doença renal crônica; estarem utilizando medicamentos do tipo bifosfonatos ou outros antirreabsortivos, antiangiogênicos, feniltoína, fenobarbitúricos e rifampicina; e, gestantes.

\section{Dosagem de vitamina $D$}

Os resultados das dosagens de vitamina $D$ dos pacientes desta pesquisa foram comparados $e$ classificados de acordo com as recomendações baseadas em evidências pelas Diretrizes de Prática Clínica da Sociedade Endócrina dos Estados Unidos (Endocrine Society's Clinical Pratice Guidelines). Grupo D (Deficiência em vitamina $\mathrm{D})=25$-Dyhydroxyvitamin $\mathrm{D}(25-(\mathrm{OH}) \mathrm{D})<20 \mathrm{ng} / \mathrm{ml}$; Grupo I (Insuficiência de vitamina $D)=25-(\mathrm{OH}) \mathrm{D}$ entre $21-29 \mathrm{ng} / \mathrm{ml}$; e Grupo $\mathrm{S}$ (Suficiente em vitamina $\mathrm{D}$ ) $=25-(\mathrm{OH}) \mathrm{D}$ entre 30 $100 \mathrm{ng} / \mathrm{ml}$ (HOLICK MF, et al. 2011).

A coleta necessária para este exame foi de $2,0 \mathrm{ml}$ de sangue, sendo realizada 15 dias antes da data do procedimento cirúrgico. Todas as análises sanguíneas foram realizadas em parceria com a Unidade de Pesquisa Clínica da Universidade Federal Fluminense. Além do exame de 250HD3 necessário para verificar o nível de vitamina $\mathrm{D}$, foi fornecido ao participante da pesquisa o hemograma completo, o tempo de coagulação, o tempo de sangramento e a taxa de glicose, que são os exames exigidos na clínica de implantodontia da UFF, bem como o lipidograma e telopeptídeo C-terminal do colágeno tipo 1 (CTX) que é um biomarcador sanguíneo ósseo.

Os grupos da pesquisa foram estabelecidos de acordo com os resultados dos níveis sanguíneos de $25 \mathrm{OH}$ (vitamina D) em Grupo Insuficiência de vitamina D, N=3 e Grupo Controle (Suficiente em vitamina D), $\mathrm{N}=5$.

\section{Análise da Expressão Gênica}

No momento da cirurgia para instalação do implante endósseo, os alvéolos cirúrgicos foram submetidos à coleta de sangue, com ponta de papel absorvente, durante 30 segundos, para análise da expressão gênica dos genes RANKL (fator 11 da superfamília TNF ou ligante de RANK), OPG (osteoprotegerina ou membro $11 \mathrm{~b}$ da superfamília de receptor TNF).

Após a coleta da amostra, as pontas de papel absorvente foram armazenadas em tubos eppendorf contendo $1 \mathrm{ml}$ de Trizol $\AA^{\circ}$ (InvitrogenTM por Life Technologies, Nova lorque, NY, EUA). O RNAm total foi extraído das amostras pelo método convencional do Trizol® (InvitrogenTM por Life Technologies, Nova Iorque, EUA). Foi realizado o tratamento com DNase, para digerir o DNA genômico que poderia levar a falsos resultados positivos, usando DNA-freeDNase ${ }^{\circledR}$ (Ambion por Invitrogen ${ }^{\mathrm{TM}}$ pela Life Technologies, NY, EUA). A integridade do RNA foi confirmada e corrida em eletroforese, gel de agarose a $1,2 \%$ corada com SYBR Stain $\AA^{8}$ (InvitrogenTM pela Life Technologies, NY, EUA). A pureza do RNA foi confirmada com a razão das absorvâncias 260/280 em spectrophotômetro, e a quantidade de RNA estimada a $260 \mathrm{~nm}$ (Nanodrop® 1000, ThermoScientific, Wilmington, EUA).

A reação de transcrição reversa do $P C R(R T-P C R)$ foi realizada para a síntese de DNA complementar (cDNA), a partir de $300 \mathrm{ng}$ de RNA utilizando o High-capacity cDNA reverse transcripitase kit com RNase inibidor (Applied Biosistems, Foster City, CA, EUA), de acordo com o protocolo do fabricante. O controle do branco (RT-PCR, sem matriz de RNA) e as reações RT (reações de PCR sem a transcrição reversa) foram executadas juntamente com todos os RT-PCRs. As reações de PCR quantitativo (qPCR) foram realizadas no software MxPro-Mx3005P (Stratagene/Agilent Technologies, Wilmington, DE, EUA), utilizando o sistema de detecção rápida SYBR Green Master Mix (Applied Biosystems, Foster City, CA, EUA) com 1,5 $\mu \mathrm{l}$ de CDNA em cada reação. Utilizou-se o $q P C R$ com ativação a $95^{\circ} \mathrm{C}$ durante 10 minutos, seguido por 40 ciclos de desnaturação e prolongamento $\left(95^{\circ} \mathrm{C}\right.$ durante 15 segundos e $60^{\circ} \mathrm{C}$ durante 1 minuto).

Iniciadores específicos para RANKL e OPG (Tabela 1) foram confeccionados com base nos dados BLAST (http: //blast.ddbj. nig.ac.jp/top-j.html). O Método Livak (2- $\Delta \triangle C T$ ) determinou a quantificação relativa da expressão desses genes. Os valores foram normalizados em relação à expressão constitutiva de $\beta$ actina. 
Tabela 1 - Sequência dos iniciadores utilizados para análise de expressão por qPCR para os genes OPG, RANKL e o controle $\beta$-actina.

\begin{tabular}{ccc}
\hline Gene & Primer Senso & Primer Reverso \\
\hline OPG & 5'-AGGAGCTGCAGTACGTCAAG-3' & 5'-TCTGGGGTTCCAGCTTGC-3' \\
RANKL & 5'-GCAGAGAAAGCGATGGTGGA-3' & 5'-GGAACCAGATGGGATGTCGG-3' \\
B-actina & 5'-AATTACGAGCTGCGTGTGG-3' & 5'-AGAGCGCAGGTAGGATAGCA-3' \\
\hline
\end{tabular}

Fonte: Santos TAB, et al., 2020.

\section{Análise Estatística}

O processamento dos dados e a análise estatística foram realizados utilizando-se o programa Graph Pad Prism 6.0, 2017 (CA, USA). O teste de Shapiro-Wilk foi usado para avaliar a distribuição das variáveis. O teste exato de Fisher foi usado para comparar as variáveis nominais e o teste de Mann Whitney foi usado para comparação das variáveis numéricas entre os grupos, incluindo análise de expressão gênica após cálculo pelo método $2^{-\Delta \Delta \mathrm{CT}}$. Os valores de $\mathrm{p}<0.05$ foram considerados estatisticamente significativos, com intervalo de confiança de $95 \%$ (IC).

\section{RESULTADOS}

Oito participantes de pesquisa foram incluídos neste estudo, cinco do grupo controle e três do grupo teste (insuficiência de vitamina $D$ ). Não houve diferença entre gênero ( $p$-valor $=1.00$ ), assim como não houve diferença entre as médias de idade $(p$-valor $=0.40)$ e exposição solar $(p$-valor $=1.00)$ na comparação entre os grupos (Tabela 2).

Tabela 2 - Dados demográficos.

\begin{tabular}{|c|c|c|}
\hline Parâmetros & Controle $(\mathrm{N}=5)$ & $\begin{array}{l}\text { Insuficiência de vitamina D } \\
(\mathrm{N}=3)\end{array}$ \\
\hline
\end{tabular}

\begin{tabular}{|c|c|c|c|}
\hline Sexo & & & \\
\hline $\begin{array}{l}\text { Masculino } \\
\text { Feminino }\end{array}$ & $\begin{array}{l}2(40.00 \%) \\
3(60.00 \%) \\
\end{array}$ & $\begin{array}{l}1(33.33 \%) \\
2(66.67 \%)\end{array}$ & $1.00(1.33 ; 0.07-26.64)$ \\
\hline \multicolumn{4}{|l|}{ Etnia } \\
\hline $\begin{array}{l}\text { Branco } \\
\text { Pardo }\end{array}$ & $\begin{array}{l}4(80.00 \%) \\
1(20.00 \%) \\
\end{array}$ & $\begin{array}{c}0(00.00 \%) \\
3(100.00 \%)\end{array}$ & $0.14(21 ; 0.64-690.60)$ \\
\hline \multicolumn{4}{|l|}{ Idade } \\
\hline Média & $54.25 \pm 7,43$ & $47.33 \pm 3.09$ & 0.40 \\
\hline \multicolumn{4}{|l|}{ ^^Doenças sistêmicas } \\
\hline $\begin{array}{l}\text { Sim } \\
\text { Não }\end{array}$ & $\begin{array}{l}2(40.00 \%) \\
3(60.00 \%)\end{array}$ & $\begin{array}{l}2(66.67 \%) \\
1(33.33 \%)\end{array}$ & $1.00(0.33 ; 0.02-6.66)$ \\
\hline \multicolumn{4}{|l|}{ Tratamento médico } \\
\hline $\begin{array}{l}\text { Sim } \\
\text { Não }\end{array}$ & $\begin{array}{l}3(60.00 \%) \\
2(40.00 \%) \\
\end{array}$ & $\begin{array}{l}2(66.67 \%) \\
1(33.33 \%)\end{array}$ & $1.00(0.33 ; 0.02-6.66)$ \\
\hline \multicolumn{4}{|l|}{ Uso de medicação } \\
\hline $\begin{array}{l}\text { Sim } \\
\text { Não }\end{array}$ & $\begin{array}{l}4(80.00 \%) \\
1(80.00 \%)\end{array}$ & $\begin{array}{l}2(66.67 \%) \\
1(33.33 \%)\end{array}$ & $1.00(2.00 ; 0.08-1.63)$ \\
\hline \multicolumn{4}{|l|}{ Exposição ao sol } \\
\hline $\begin{array}{l}0 \times \text { semana } \\
3 \times \text { semana }\end{array}$ & $\begin{array}{l}4(80.00 \%) \\
1(20.00 \%)\end{array}$ & $\begin{array}{l}3(100.00 \%) \\
0(00.00 \%)\end{array}$ & $1.00(0.43 ; 0.01-14.09)$ \\
\hline \multicolumn{4}{|l|}{ Uso de protetor solar } \\
\hline $\begin{array}{l}\text { Sim } \\
\text { Não }\end{array}$ & $\begin{array}{l}3(60.00 \%) \\
2(40.00 \%)\end{array}$ & $\begin{array}{c}0(00.00 \%) \\
3(100.00 \%)\end{array}$ & $0.46(5.00 ; 0.17-146.8)$ \\
\hline
\end{tabular}

Legenda: *OR: Razão de probabilidade (Odds ratio); IC: Intervalo de Confiança. ${ }^{*}$ Hipertensão; Câncer. Estatística: Fisher's exact test ou Mann Whitney test.

Fonte: Santos TAB, et al., 2020. 
Foram realizadas análises da expressão gênica de $m R N A$ para os genes $O P G$ e $R A N K L$. O resultado de expressão gênica de mRNA para a razão de OPG/RANKL não foi significante quando comparados os grupos Controle e Insuficiência de vitamina $D(p=0.78)$ (Gráfico 1A). Não houve também diferença estatística entre os grupos, em relação à análise de expressão gênica de $O P G(p=0.5)$ (Gráfico 1B). Assim como não houve diferença estatística entre os grupos controle e insuficiência de vitamina $D$, em relação à análise de expressão gênica de RANKL ( $\mathrm{p}=0.5$ ) (Gráfico 1C).

Gráfico 1 - Análise da expressão gênica de mRNA dos genes OPG e RANKL.
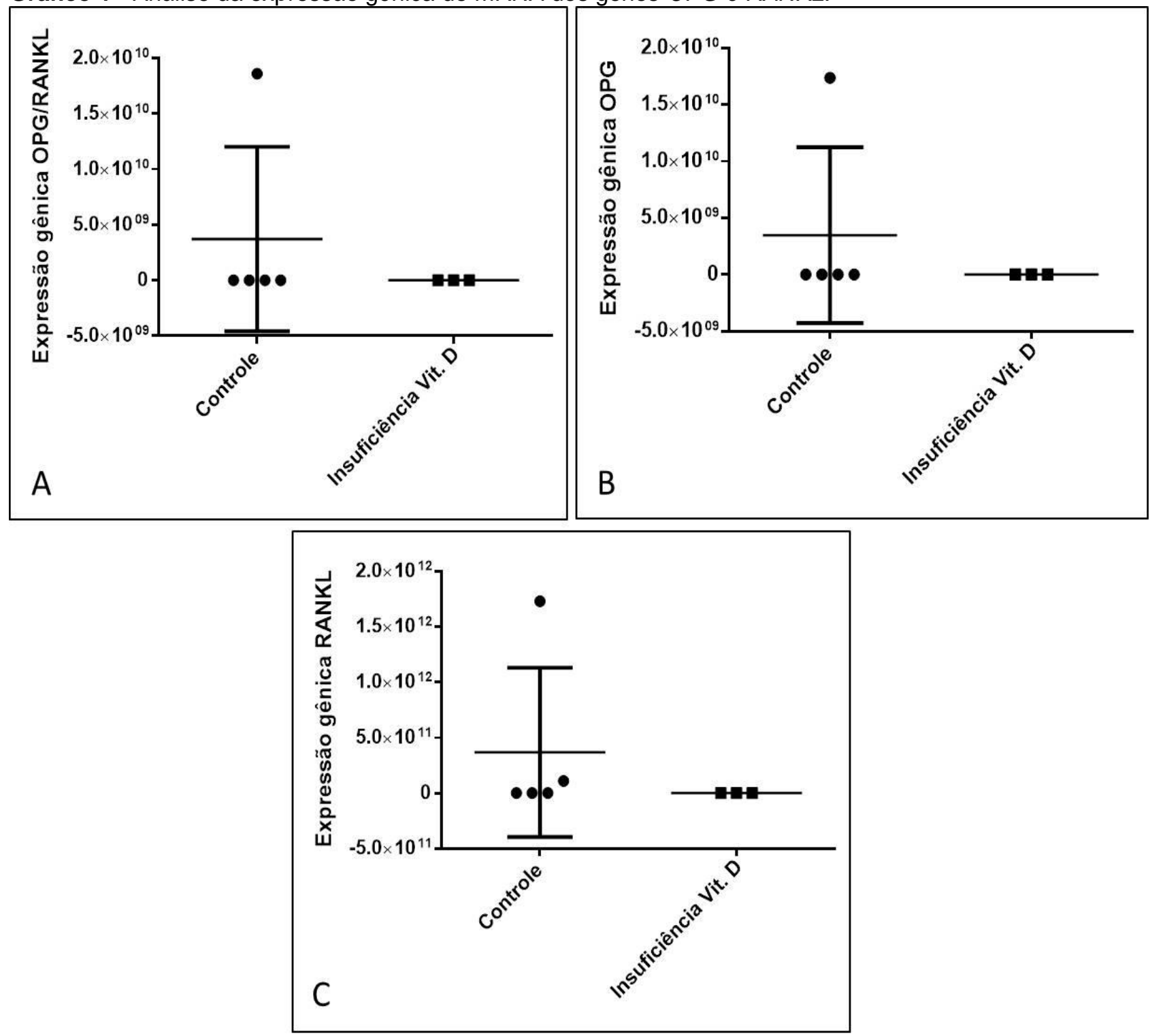

Legenda: Gráfico 1A. Análise da expressão gênica de $m R N A$ para a razão de $O P G / R A N K L$. Gráfico 1B. Análise da expressão gênica de $m R N A$ para OPG. Gráfico $1 \mathrm{C}$. Análise da expressão gênica de $m R N A$ para RANKL.

Fonte: Santos TAB, et al., 2020.

\section{DISCUSSÃO}

Apesar dos crescentes índices de alterações nos níveis de vitamina D na população mundial (MAEDA SS, et al., 2014), até o momento, a real correlação entre os níveis séricos de 25-(OH)D (vitamina D) e suas consequências na remodelação óssea foi pouco estudada. Sendo assim, o objetivo deste estudo foi verificar se os níveis de vitamina $D$ tem correlação com os níveis intraósseos de OPG/RANKL. Nossa metodologia considerou a coleta de amostras de sangue intraósseo, em pacientes saudáveis, e correlacionou os níveis 
locais de $O P G / R A N K L$, principais proteínas relacionadas à remodelação óssea, com as alterações de 25$(\mathrm{OH}) \mathrm{D}$ sérica diagnosticadas nos participantes da pesquisa. Com isso, observamos que, mesmo na presença de insuficiência de vitamina $\mathrm{D}$, não houve alteração significativa dos níveis de $O P G / R A N K L$.

Os procedimentos que englobam a prática clínica na Odontologia são intimamente relacionados com o metabolismo ósseo, seja do ponto de vista regenerativo, reabsortivo, patológico ou diagnóstico. Neste contexto, o entendimento do metabolismo ósseo, in situ, e sua associação com a característica clínica hematológica dos níveis de vitamina $\mathrm{D}$, poderiam corroborar com protocolos diversos da prática clínica. Além disso, a caracterização dos níveis de vitamina $D$ sérico é de fácil acesso por parte do cirurgiãodentista, o que possibilitaria ter uma previsibilidade nos procedimentos associados ao osso. No entanto, a maioria dos estudos considerando a ação óssea da vitamina D é experimental e em animais (ALVIMPEREIRA F, et al., 2008; KELLY J, et al., 2009; LIU W, et al. 2014; MANGANO F, et al., 2018), com poucos estudos clínicos em humanos (HEANEY RP, 2003; ALVIM-PEREIRA J, et al., 2008; DUTZAN N, et al., 2009).

Nosso estudo foi um estudo clínico prospectivo, duplo-cego, que avaliou a expressão de OPG/RANKL no meio intracelular, em células do microambiente ósseo mandibular, na insuficiência de 25-(OH)D. Do ponto de vista genético, a expressão do RNAm representa o potencial celular na produção de proteínas relacionadas com seus alvos extracelulares, sendo neste caso, osteoblastos e osteoclastos (NUSSBAUM $\mathrm{RL}$, et al., 2016). Para conseguir a eficiência máxima de vitamina $\mathrm{D}$ induzida por transporte de cálcio intestinal, as concentrações séricas de 25(OH)D devem ser de pelo menos $78 \mathrm{nmol} / \mathrm{L}$ (30 ng/mL) (HEANEY $\mathrm{RP}, 2003)$. Quando existe insuficiência de cálcio na dieta, 1,25(OH)2D interage com o seu receptor em osteoblastos e induz a expressão do receptor ativador do factor nuclear-қB ligante (RANKL), que interage com o seu receptor em pré-osteoclastos, induzindo-os a tornarem-se osteoclastos maduros (HOLICK MF, 1994; HOLICK MF, 2003 (b)).

A deficiência de vitamina $D$ resulta na diminuição de concentrações de cálcio ionizado, que são imediatamente reconhecidos pelo sensor de cálcio nas glândulas paratireóides (BROWN EN, et al., 1995). Isto resulta num aumento da expressão, produção e da secreção de PTH. O PTH ajuda a manter o metabolismo do cálcio, aumentando a reabsorção tubular de cálcio nos rins, aumentando a produção de 1,25(OH)2D3, e interagindo com osteoblastos para aumentar o sistema de receptor ativador nuclear de fator -қВ ligante $(R A N K L)$, semelhante ao 1,25(OH)2D. Este sistema reacional baseado nos baixos níveis de vitamina D ocasiona, como resultado, uma maior gênese e ativação de osteoclastos (HOLICK MF, 2004). Clinicamente, a consequência mais provável seria o aumento da reabsorção óssea ou diminuição da regeneração óssea associada ao metabolismo de $R A N K L$. Por isso, apesar dos resultados do nosso estudo não mostrarem diferença estatística significativa nos níveis de $O P G / R A N K L$, é esperado que essa diferença ocorra caso a amostra seja maior.

Em teoria, populações tropicais deveriam ter níveis séricos satisfatórios de $25(\mathrm{OH}) \mathrm{D}$ (colecalciferol). Porém, não é uma realidade nacional, apesar de vivermos num país tropical, a população brasileira ainda apresenta crescentes índices de insuficiência de vitamina D (MAEDA SS, et al., 2014). Além disso, populações de todos os continentes têm baixos níveis séricos de vitamina $D$ com taxas alarmantes de epidemia que podem ser consideradas uma pandemia e um sério problema de saúde global (MITHAL A, et al., 2009; MAEDA SS, et al., 2014). Provavelmente devido à falta de exposição à luz solar (indivíduos na idade adulta normalmente estão confinados em salas e escritórios no horário de maior incidência solar) ou ausência de absorção da luz solar (os idosos não absorvem bem a radiação UVB).

A exposição solar ideal para os seres humanos seria de 20 minutos nas áreas da face, mãos, braços e pernas, sem o uso de protetores solares, no período entre 11:00 e 13:00 horas. Neste intervalo de tempo, há grande disponibilidade de radiação UVB em comprimentos de onda ideais (297nm) para promover a fotólise do 7-dehidrocolesterol do anel B (Pró-vitamina D) encontrado na pele, para futura disponibilidade da forma ativa de 1,25a (OH) 2D3 (Calcitriol) em células e órgãos, produzindo seus efeitos (HOLICK MF, 2004; NAVAB M, et al., 2004; FENTOĞLU O, et al., 2011). No entanto, o uso excessivo de protetor solar e 
recomendações da não exposição neste período, como forma de evitar o câncer de pele, minimizaram a possibilidade de produção natural de calcitriol. Na prática, há uma tendência de suplementação com vitamina $\mathrm{D}$, de forma a minimizar os possíveis danos decorrentes de sua deficiência.

Clinicamente, a suplementação da vitamina $D$ tem sido estudada em Odontologia, principalmente relacionada à osseointegração de implantes dentários. Considerando os efeitos benéficos desta vitamina no metabolismo ósseo, estudos exploram a suplementação pré-cirúrgica como possível indicação para melhorar a regeneração óssea em pacientes com níveis inadequados de vitamina $D$. O estudo de Mangano $F$, et al. (2018), afirmou que a deficiência e a insuficiência de $25-(\mathrm{OH}) \mathrm{D}$ podem exigir uma suplementação oral de vitamina $D$, durante semanas antes da colocação do implante, a fim de eliminar os níveis deficientes de $25-(\mathrm{OH}) \mathrm{D}$ no sangue.

Outros estudos demonstraram que a deficiência de vitamina $D$ pode comprometer a ossificação dos implantes e que a suplementação de vitamina $D$ pode estimular a formação óssea e, consequentemente, aumentar o contato ósseo entre uma superfície de implantes de titânio e osso (BLAIZOT A, et al., 2009; SAKAI S, et al., 2009). Em um estudo, in vivo, com roedores portadores de doença renal, foi possível verificar, após análise de dois anos na interface osso-implante, que o volume ósseo ao redor do implante e a resistência do implante à remoção foram melhorados pela suplementação de vitamina D (LIU W, et al. 2014).

Estudos recentes mostraram uma melhora na osseointegração do implante dentário com o revestimento da superfície do implante com vitamina D (MANGANO F, et al., 2016; MANGANO F, et al., 2018). No entanto, ainda não há comprovação científica de que a suplementação de D pode influenciar no contato do osso no implante ou qualquer informação biológica in situ que justifique o uso de suplementação.

Os resultados deste estudo não evidenciaram influência dos níveis de vitamina $D$ sérico sobre os níveis de OPG/RANKL intraósseo. No entanto, como este é um estudo piloto, com número de participante de pesquisa reduzido, sugere-se a realização de futuras pesquisas incluindo maior número de participantes de pesquisa, inclusive oriundos de diferentes regiões do país.

\section{CONCLUSÃO}

Os resultados de estudo, considerando suas limitações, não evidenciaram uma correlação direta entre a remodelação óssea e os níveis séricos de vitamina $D$. Contudo, considerando a importância da vitamina $D$ na homeostase óssea, observa-se a necessidade de realizar outros estudos que avalie o papel da vitamina D na osteointegração de implantes odontológicos. Para isso, é necessária a inclusão de um maior número de participantes de pesquisa, o que não foi possível nesta pesquisa devido à dificuldade de incluir participantes que cumprissem todos os critérios de inclusão.

\section{AGRADECIMENTOS}

Os autores agradecem a todos os pacientes que aceitaram participar deste projeto, agradecem a assistência do curso de Pós-graduação em Implantodontia da Faculdade de Odontologia da Univerdidade Federal Fluminense, Niterói. E agradecem a assistência da Unidade de Pesquisa Clínica da Universidade Federal Fluminense.

\section{REFERÊNCIAS}

1. ADELL R, et al. A 15-year study of osseointegrated implants in the treatment of the edentulous jaw. Int $\mathrm{J}$ Oral Surg, $1981 ; 10(6): 387-416$.

2. ALVIM-PEREIRA F, et al. Analysis of association of clinical aspects and vitamin $D$ receptor gene polymorphism with dental implant loss. Clin Oral Implants Res, 2008; 19(8): 786-795.

3. ARAÚJO MG, et al. Alveolar socket healing: what can we learn? Periodontol 2000; 2015; 68(1): 122-134.

4. BALOUL, SS. Osteoclastogenesis and osteogenesis during tooth movement. Frontiers of Oral Biology, 2016; 18: 7579.

5. BARTOLD PM, et al. Mechanisms and control of pathologic bone loss in periodontitis. Periodontol 2000, 2010; 53: 55-69. 
6. BAUD'HUIN M, et al. RANK, RANKL osteoprotegerin: key partners of osteoimmunology and vascular diseases Cell Mol Life Sci, 2007; 64: 2334-2350.

7. BLAIZOT A, et al. Periodontal diseases and cardiovascular events: meta-analysis of observational studies. Int Dent J, 2009; 59: 197-209.

8. BOONSIRISETH K, et al. Bone and soft tissue healing in dental implantology. Journal of Medicine and Medical Sciences, 2014; 5(5): 121-126.

9. BOUILLON R, et al. Structure-function relationships in the vitamin D endocrine system. Endocr Re, 1995; 16(2): 200257.

10. BOUILLON R, et al. Vitamin D and human health: lessons from vitamin D receptor null mice. Endocr Rev, 2008;29(6): 726-776.

11. BROUGHTON G, et al. The basic science of wound healing . Plast Reconstr Surg, 2006; 117(7 Suppl): $12 \mathrm{~S}-34 \mathrm{~S}$.

12. BROWNET EM, et al. Calcium-ion-sensing cellsurface receptors. N Engl J Med, 1995;333:234-240.

13. CARREL A, BURROWS MT. Cultivation of Adult Tissues and Organs Outside of the Body. J.A.M.A, $1910 ; 55: 1379$.

14. Clark DA. The Capability Approach: Its Development, Critiques and Recent Advances. GPRG-WPS, $2005 ; 032: 1-18$.

15. COCHRAN DL. Inflammation and bone loss in periodontal disease. J Periodontol, 2008; 79: 1569-1576.

16. COSTA LC, et al. Chronic periodontitis and RANKL/OPG ratio in peri-implant mucosae inflammation. Brazilian Dental Journal, 2018; 29(1): 14-22.

17. DUTZAN N, et al. Over-expression of forkhead box P3 and its association with receptor activator of nuclear factorkappa B ligand, interleukin (IL) $-17, \mathrm{IL}-10$ and transforming growth factor-beta during the progression of chronic periodontitis. J Clin Periodontol, 2009; 36: 396-403.

18. FENTOĞLU O, et al. Serum lipoprotein associated phospholipase A2 and C-reactive protein levels in association with periodontal disease and hyperlipidemia. J Periodontol, 2011; 82:350-359.

19. HEANEY RP. Long-latency deficiency disease: insights from calcium and vitamin D. Am J Clin Nutr, 2003; 78: 912919.

20. HOLICK MF, LECTURE MA. Vitamin D: new horizons for the 21st century. Am J Clin Nutr, 1994; 60: 619-630.

21. HOLICK MF. Vitamin D: a millennium perspective. J Cell Biochem, 2003(a); 88: 296- 307.

22. HOLICK MF. Vitamin D: importance in the prevention of cancers, type 1 diabetes, heart disease, and osteoporosis. Am J Clin Nutr, 2004; 79: 362-371.

23. HOLICK MF. Vitamin D: photobiology, metabolism, mechanism of action, and clinical applications. In: Favus M, ed. Primer on the metabolic bone diseases and disorders of mineral metabolism. 5th ed. Washington, DC: American Society for Bone and Mineral Research, 2003(b):129-137.

24. KELLY J, et al. Vitamin D and bone physiology: demonstration of vitamin D deficiency in an implant osseointegration rat model. J Prosthod, 2009; 18(6): 473-478.

25. KHOSLA S. The OPG/RANKL/RANK system. Endocrinology, 2001;142: 5050-5055.

26. LIMA RSR, SEABRA FRG. O enxerto de osso em neoformação na era da Odontologia-Baseada em Evidências. Odontol Clín-Cient, 2010; 9(3): 201-204.

27. LIU W, et al. Vitamin D supplementation enhances the fixation of titanium implants in chronic kidney disease mice. PLoS One, 2014; 9(4): e95689.

28. MAEDA SS, et al. Recomendações da Sociedade Brasileira de Endocrinologia e Metabologia (SBEM) para o diagnostic e tratamento da hipovitaminose D. Endocrinol Metab, 2014; 58(5): 411-433.

29. MANGANO F, et al. Is Low Serum Vitamin D Associated with Early Dental Implant Failure? A Retrospective Evaluation on 1625 Implants Placed in 822 Patients. Mediators Inflamm, 2016; 2016 (5319718): 1-7.

30. MANGANO $F$, et al. Low serum vitamin $D$ and early dental implant failure: Is there a connection? A retrospective clinical study on 1740 implants placed in 885 patients. J Dent Res Dent Clin Dent Prospect, 2018; 12(3): $174-182$.

31. MINE Y, et al. Mimuralmpact of titanium ions on osteoblast-, osteoclast- and gingival epithelial-like cells $\mathrm{J}$ Prosthodont Res, 201; 54: 1-6.

32. MITHAL A, et al. Global vitamin D status and determinants of hypovitaminosis D. Osteoporos Int, 2009 ;20(11): 18071820.

33. NAVAB M, et al. The oxidation hypothesis of atherogenesis: the role of oxidized phospholipids and HDL. Lipid Res. 2004; 45: 993-1007.

34. NORMAN AW. From vitamin D to hormone D: fundamentals of the vitamin $D$ endocrine system essential for good health. Am J Clin Nutr, 2008; 88(suppl): 491S-499S.

35. NUSSBAUM RL, et al. Thompson \& Thompson Genética Médica. 8a ed. Rio de Janeiro: Elsevier, $2016 ; 560$ p.

36. ORGILL D, DEMLING RH. Current and approuches to wound to healing. Crit. Care Med. 16: 899-908, 1988.

37. RUIZ-IRASTORZA G, et al. Vitamin D deficiency in systemic lupus erythematosus: prevalence, predictors and clinical consequences. Rheumatology, 2008; 47(6): 920-923.

38. SAKAI S, et al. 1- $\alpha$-25-dihydroxy vitamin D3 inhibits osteoclastogenesis through IFN- $\beta$-dependent NFATc1 suppression. J Bone Miner Metab, 2009; 27: 643-652.

39. TAZIMA MFGS, et al. Biologia da ferida e cicatrização. Medicina, 2008; 41 (3): 259-264.

40. THEILL LE, et al. RANK-L and RANK: T cells, bone loss, and mammalian evolution. Annual Review of Immunology, 2002; 20: 795-823. 